NASA Technical Memorandum 71

\title{
$-\frac{1}{1}$
}

NASA Technical Memorandum 71

(NASA-TM-78595; FUEL-CONSEEVATIVF GUIDANCE

SISTE FCF POWEGEC-LIFT AIECPAFT (NASA)
I $P$ HC AC, ME AOI

N79-26009

CSCL $01 \mathrm{C}$

Inclas

63/01 23434

\section{Fuel-Conservative Guidance System for Powered-Lift Aircraft}

Heinz Erzberger and John D. McLean

June 1979

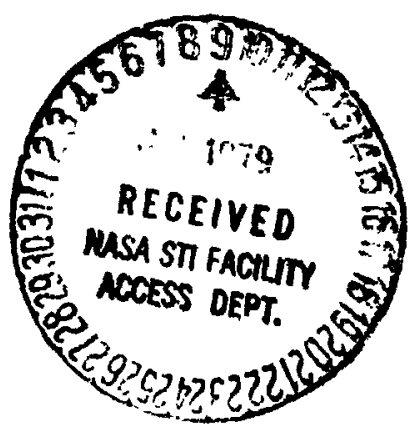


NASA Technical Memorandum 78595

\section{Fuel-Conservative Guidance System for Powered-Lift Aircraft}

ileinz Erzberger

John D. McLean, Ames Research Center, Moffett Field, California 


\section{Abstract}

A concept for automatic terminal-area guidance, comprising tho modes of operation, has been developed and evaluated in flight tests. In the first or prejictive mode, fuel-efficlent approach trajectories are synthesized in fast time. In the second or tracking mode, the synthesized trajectories are reconstructed and tracked automatically. An energy rate performance model derived from the lift, drag, and propulsion-system characteristics of the aircraft is used in the synthesis algorithm. The method optimizes the trajectory for the initial aircraft position and wind and temperature profiles encountered during each landing approach. The paper describes the design theory and discusses the results of simulations and filght tesis using the Augmentor Wing Jet STOL Research Alrcraft.

\section{List of Symbols}

D

$d_{b}, d_{f}$

d

$d_{h}$

E

$\dot{\mathrm{E}}_{\mathrm{n}}$

$\dot{\mathrm{E}}_{\mathrm{nmax}}, \dot{\mathrm{E}}_{\mathrm{nm1n}}$

F. G

8

h

$h_{f}, h_{1}$

k

$k_{\phi y}, k_{\phi \dot{y}}$

$\mathbf{L}$

$\dot{\mathbf{s}}$

I

t

$\mathbf{u}$

$$
\begin{aligned}
& \text { = drag force, } 1 b \\
& \text { = distance of backward and forward } \\
& \text { integration, respectively } \\
& \text { - cruise distance, ft } \\
& \text { - length of ground track from initial } \\
& \text { - energy, ft } \\
& \text { = energy rate, } f t / \mathrm{sec} \\
& \text { - maximum and minimum available } \\
& \text { energy rate, respectively, } f t / s e c
\end{aligned}
$$

*Research Scientiat. Member AIAA.

This paper is declared a work of the U.S. Government and therefore is in the public domain. $u_{c}$

$\mathrm{v}_{\mathrm{a}}$

$v_{a f}, v_{a 1}$

$\mathrm{v}_{\mathrm{w}}$

W

$\mathbf{x}$

$x_{f}, x_{1}$

$y_{f}, y_{i}$

a

$Y$

$Y_{a}$

$\Delta \dot{\mathbf{v}}_{\mathbf{a}}$

$\Delta y$

$\Delta \dot{y}$

$\delta_{f}$

$\delta$ fmax

$\theta_{c}$

v

$\pi$

$\phi_{c}, \phi_{\mathrm{r}}$

$\psi_{f}, \psi_{1}$
- a1rcraft control vector

- alrspeed, ft/sec or knots

- final and initial airspeeds of aircraft, respectively, $f t / s e c$ or knots

- wind speed in direction of ground track, knots

- a1rcraft weight, $1 b$

- perturbation state vector

- final and initial x coordinates of alrcraft, respectively, ft

- final and initial y coordinates of alicraft, respectively, ft

- angle of attack, deg

- Inertial filght-path angle, deg

- Aerodynamic flight-path angle, rad or deg

- airspeed rate correction due to wind shear, $\mathrm{ft} / \mathrm{sec}^{2}$

- crosstrack error, ft

- crosstrack error rate, $\mathrm{ft} / \mathrm{sec}$

- flap angle, deg

= maximum flap angle, deg

- fraction of energy rate used for changing speed

- comnand pitch angle, deg

- vectored thrust, in degrees of nozzle angle

- throttle setting, in percent RFM

- fraction of available energy rate

= commanded and reference bank angles, respectively, deg

- final and Inftial ground heading of alrcraft, respectively, deg

Introduction.

In the past, terminal-area guidance system design for alrcraft has concentrated primarlly on automatic glide slope tracking, flare, and touchdown. During recent years, designs have teen developed to provide autcmatic guidance along curved and decelerating approach paths. I This increased capability was made possible through the integration of digital computers into the flight guldance system. However, even in the more advanred designs, automatic 
guidance is 1 imited to a few prestored threedimensional flight paths, as in Ref. 1. While the ability to fly complex prestored trajectories is essential, it cannot give optimum performance under actual terminal-area operating conditions as shall be explained.

First, a prestored trajectory cannot optimize fuel coneumption or a similar performance measure under actual operating conditions. Optjmum trajectorles depend significantly on aircraft gross weight, wind and temperature profiles, and on the initial state of the aircraft. These varlables cannot be predicted with the required precision prior to takeoff. To prestore optimum trajectories for each of the conditions likely to be encountered wruld result in an impossibly large memory requirement. Therefore, prestored trajectorles must necessarily represent a compromise in performance.

Second, in existing systems the pilot must fly the alrcraft manually from its current position to the starting point of the trajectory. This flight segment is known as the capturing maneuver. Threedimensional, curved trafectories can be difficult to capture mancally, and, if the trajectory alco Includes s spectfication of landing time, as is the case in 4D guldance, the capturing maneuver cannot be done by the pilot without computer assistance. Therefore, the capturing maneuver, because of its varlability, can only be generated by onboard trajectory synthesis.

Third, alrcraft in high density alrspace are usually controlled by alr traffic control vectors and during this period cannor follow a prestored flight path. Synthesis of a trajectory can only begin after the aircraft has recelved its final vector and has been cleared for approach. But the initial position of the alrcraft at that time varles between approaches, thus trajections require onboard synthesis.

An initial design of a four-dimensional guidanre system embodying the concept of onboard trajectory synthesis, including an advanced capture law, was aeveloped and 1 light tested onboard a Convair 340 aircraft equipped with the STOLAND avionics. ${ }^{2}$ In the design described here, hortizontal trajectories are generated by the metlod of Reference 2 , but vertical and speed proflles are synchesized using gimplifted aero/propulsion performance models of the alrcraft. This results in profiles that are optimun for fuel conservation. Design of the control law for tracking the synthesized trajectory is based on the linearized perturbation gutdance approach. Since the perturbation equations are alrcraft configuratiun-dependent, gain scheduling is used in the feedback law.

The Augmentor Wing Jet STOL Research Alrcraft (AWJSRA) was chosen as the test vehicle for this concept. This type of pcwered-lift aircraft is highiy cost-sensitive to operational procedures in the cerminal area. It also exemplifies particularly well the unique problems of powned-lift alrcraft, namely, high fuel consumption in the STOL mode; dependence of both $11 f t$ and drag on thrust; and an excess of controls ovar the minimun number needed to determine path and opeed. These factors ugget that trajectory optimization could greatly increase the operational efficiency of the aircraft. Implewantation of this concept wa facilitated by the existing installation of the STOLAND avionics system onboard the aircraft.

Energy Rate Model and Selectlon of Kefertnce Contry?s

An energy rate model of aircraft performance has been found to yield a compact and sufficiently accurate representation of performance for terminalarea trajectory synthesis. In this section a performance model based on energy rate is derived ard then applied to determine the optimum reference controls for synthesizirg trajectories.

Consider the standard expresston for energy rate written as

$$
\frac{d E}{d t}=\frac{(T-D) V_{a}}{W}
$$

where

$$
E=h+\frac{1}{28} v_{a}^{2}
$$

with constraint $L=W(\operatorname{Ref}, 3)$. It is assumed throughout this paper that flight-path aigles are small such that $\cos Y_{a} \approx I$ and $\sin Y_{a} \approx \gamma_{a}$. Furthermore, it is assumed that flight-path angle rates are so small that their effect on lift is negligible. Differentiation of Eq. (2) with respect to time gives an equivalent expression for energy rate:

$$
\frac{d E}{d t}=\frac{d h}{d t}+\frac{1}{g} V a \frac{d V}{d t}
$$

Equations (1) and (3) can be nondimensiunalized by dividing ther both by $v_{a}$. The resulting quantity on the left side, $\left(1 / \mathrm{v}_{\mathrm{a}}\right)(\mathrm{dE} / \mathrm{dt})$, is defined as the normalized energy $r$ te $\hat{E}_{n}$, or energy rate for short. By using the relation (dh/dt) $\approx v_{3} \gamma_{2}$, the two relations for $E_{n}$ become

$$
\begin{aligned}
& \dot{E}_{n}=\frac{T-D}{w} \\
& \dot{E}_{n}=r_{a}+\frac{1}{g} \frac{d V_{a}}{d t}
\end{aligned}
$$

with constraint $\mathrm{L}=\mathrm{W}$

Equation (4) specifies the energy rate as a function of the difference between thrust and drag, subject to the constraint that lift equal weight. Thrust and drag are in turn functions of the controls producing forces in the flight-path direction, namely throttle $\pi$, flap angle $\delta_{f}$, nozzle angla $v$ (vectored thrust), and angle of attack $\alpha$. Equation (5) determines the relationship between flightpath argle and acceleration for the cnergy rate calcllated from Eq. (4). Equa:ion (5) indicates that, in particular, a giver. energy rate may be ut 1:1zed to fly at flight-path angle $\gamma_{\text {a with con- }}$ stant alrapeed, or to fly at zero flight-path angle with acceleration,$V_{a} / d t$. An Infinity of other cumbinations of $\gamma_{b}$ and $\mathrm{dV}_{\mathrm{a}} / \mathrm{dt}$ can also be chosen to yleld the same cnergy rate. Th1s makes posstble a simplifying dichotomy in the trafectory synthesis, namely, at any $t$ ime the dealred energy rate 18 selected firs: by cholce of appropriate controls and then the linearly related quantities of $Y_{a}$ and $\mathrm{dV}_{\mathrm{a}} / \mathrm{dt}$ are selected to generate the specifics of the flight path. The next section develops the complete synthesis algorithm based on this approach. Here we elaborate on the determination of the functional dtpendence of energy rate on the forceproducting controls. 
Since the STOL alrcraft studied in this paver has four controls to achieve a specified energy rate and to maintain lift equal to weight, there is an excess of two controls over the minimum number needed for a simultaneous solution to Eq. (4) and the constraint $L=W$. These two extra degrees of freedom in the controls are expluited to minimize power setting and, therefore, fuel flow at every enex gy rate. This sptimlzation problem is restated in equivalent form as the maximization of ensrgy rate fur a given power setting:

$$
\begin{gathered}
\dot{E}_{\mathbf{n}}(\pi)=\max _{v, a, \delta_{f}} \frac{T-D}{W} \\
\text { Constraint: } \quad L\left(\pi, v, \alpha, \delta_{f}\right)=W
\end{gathered}
$$

The maximization must obey various inequality constraints on the controls:

$$
\begin{aligned}
-10.5^{\circ} & <\alpha<19.5^{\circ} \\
6^{\circ} & <v<100^{\circ} \\
5.6^{\circ} & <\delta_{\mathrm{f}}<\operatorname{fmax}_{\max }\left(\mathrm{V}_{\mathrm{a}}\right) \quad \text { [Flap placard] }
\end{aligned}
$$

In addition, a lift or maneuver margin must be satisfled at every point to guarantee sufficient normal force for changing the flight path. Pllots familiar with chis alrcraft specify that at least $0.4 \mathrm{~g}$ of normal acceleration must be attalnable at any time by an increase in the angle of attack alone.

The lise of Eq. (6) results in the selection of the controls that $y$ ield the maximum attainable energy rate at each thrust setting. Th1s ensures the effictent use of thrust at any energy ra:e that requires more than the manimum thrust. But energy rates more negative than those attainable oy Eq. (6) are also of interest. Such negative er.ergy rates must occur at the greater of minimum or ldle thrusts required by the maneuver margin. At a particular airspeed, a decraase in the en-rgy rate below the minimum attained througn Eq. (6) can be effected by increasing the vectored thrist angle $v$ and/or the flap angle $\delta_{\mathrm{f}}$. The third control, angle of attack $a$, is needed to satisfy thu constraint $L=W$. The two degrees of freedom in the controls can be exploited to minimize nolse exposure along the ground track. Noise under the aircraft is known to incricase as the nozzles producing the vectored thrust are turned downward. Therefore, a further decrease in energy rate is acinleved by first increasing flap angle until it rcaches its limit or placard value and only then by lncreasing nozzle angle.

The result of applying these procedures to the AWJSRA is shown in Fig. 1 for a welght of $38,0001 \mathrm{~b}$, sea-level altitude, and staidard temperature. The f 1 gure gives the envelope of energy rate $v s$ indicated alrspeed with throttle, flaps, and vectoring nozzle 98 parameters. Angle of attack is not plotted to avoid cluttering the figure. At any airspeed, the $E_{n \max }$ and Enmin curves define the range of permissible energy rates. The opt imum controls for a given alrspeed and energy rate are determined by interpolation between contours of constant controls. For example, at an alrspeed of $105 \mathrm{knota}$ and $E_{n}=-0.17$, the optimum controls are found to be: $\delta_{f}=26^{\circ}, v=6^{\circ}, \pi=84 \%$ (point A, F1g, 1). Angle of attack (not shown) is $8.4^{\circ}$. Maximum enercy rate with minimum thrust cccurs at 112 knots (point B) and corresponis approximaiely to $(\mathrm{L} / \mathrm{D})_{\max } * 10$.

It should be noted that the force-producing controls in this experimenta? STOL a1rcraft have unusual characteristics that accounc for the relative complexity of $\mathbf{F 1 8}$. 1. Throttle affects both lift and drag at all speeds, but the effect on lift is greatest in the STUL regime below about 80 knots. The thrust magnitude produced by the vectoring nozzle, referred to as the hot thrust, is also cor rolled by the throttle and accounts for about $60 \%$ of the total thrust produced by the two engines. The remaining $40 \%$ of the thrust which is the cold thrust produced by the fans, encrglies the augmentor wing to increase lift at STOL syeeds.

The relationship between the controls and the energy rate is revealed more clearly in F1g. (2) at the example atrspeed of 105 knots. Many such plots at varlous alrspeeds would be required to 1llustrate the complete dependence of the coutrols on energy rate. As the energy rate decreases below 1ts maximum value of 0.28 , throttle decreases nearly linearly until idle throttle is reached. In this Interval flaps Increase only slightly while nozzle angle romains at mintmum and angle of attack increases. At more negative energy rates, flaps become the dowinant control unt 11 they reach the placard value of $40^{\circ}$ at this airspeed. Angle of attact: decreases sharply as flap angle increases. Fi.rally, nozzle angle increases toward its maximum value of $100^{\circ}$ as the energy rate decreases toward its negative limit of -0.3 .

In the flight implementation of the algorithm, four diagrams as shown in $\mathrm{FIg} .1$ are utfilzed, two for sea-level altitude at weights of 38,000 and $48,0001 \mathrm{~b}$ and two others for 5000-ft altitude at similar weights. Experience indicates that these are sufficient data to interpolate the controls adoninately, Each diagram requires i24 words of memory in the airborne computer. The small circles in Fig. 1 indicate the locations of points that are stored. The energy rate data are also corrected for deviations from the standard temperature profile. Correction is done by computing a thrust setting corrected for temperature devlations.

\section{Synthesis of Complete Profiles}

In the preceding section the criteria of fuel conservation and noise reduction were used to determine the four refer ...e controls of throttle, nozzle angle, flap angle, and angle of attack as functions of the energy rate. This approach replaced the problem of selecting four control variables with the simpler problem of selecting a single, equivatent variable, namely, the energy rate. In this section we make use of the energy rate variable in generating efficlent terminal-area trajectories.

Tha problem of cerminal-area-trajectory synthesis can be stated as the specification of ruies for flying an alrcraft with initial state vector $\left[x_{1}, y_{1}, h_{i}, \psi_{1}, v_{a 1}\right]$ to a final state vector $\left[x_{f}, y_{f}, h_{f}, \psi_{E}, v_{a f}\right]$. To be of practical interest, such rules must generate efflcient and flyable trajectories connecting various initial and final state vectors. By specifying a performance criterion such as fuel consumption, we can fit this problem into the framework of optimal control theory. However, the difficulty of soiving an optimal control problew characterlzed by a flve-element state vector makes this approach computationally impractical for In-flight implementation. Following Ref. 4, we have 
adopted the simplifying procedure of separating the synthesis problem into two essentially indepandent problems.

The first problem consists of synthesizing the horizontal or $2 D$ trajectory. References 4 and 5 give several algorithms for computing near-minimumdistance $2 \mathrm{D}$ trajectorles as $\approx$ sequence of an initial constant radius turn, straight flight, and a final constant radius turn, where the turn cadil are chosen so as to avoid exceeding a specified maximum bank angle at the maximum ground speed encountered in each turn. A description of the algorithm used in the flight implementation can be found in Ref. (5). Figure 3 illustrates the 2D trajectories computed by the al gorlthm for several initial positions, $P_{1}$, in the terminal area. Note that the terminal point, $P_{f}$, lies on an extension of the runway centerline, and that the heading angle $\psi \mathrm{f}$ of all trajectories is equal to the runway heading at that point. Thus, the algorilhm always generates 2D trajectories that match the Initial and final state vector components $x_{1}, y_{1}, \psi_{1}$ and $x_{f}, y_{f}, \psi_{f}$.

The second problem, solved after the horizontal trajectory has been computed, consists of cynthes1zing efficient speed and altitude profiles which match the initial and final speeds and altitudes $v_{i}, h_{i}$, and $v_{f}, h_{f}$, ressectively.

The horizontal distance of the trajectory $d_{h}$, a known quantity computed in the previous step, adds a third boundary condition to be satisfied by the protiles. While this three-state optimal-control problem is much simpler to solve than the uriginal five-state problem, it is still too complex for onboar's-computer implementation. A simpler algorithm was therefore developed that generates nearontimym sneed-altitude profiles by matching the general characterisics of optimum fuel and noise trajectories studied in Refs. 6 and 7, respectively. We briefly explain the rationale for this algorithm with reference to descent, which is the most difficult case.

It was found in Ref, 6 that the descent portion of a minimum fuel descent trajectory is characterized by a delay in the start of the energy decrease as long as possible consistent with meet ing end constraints of speed and allitude. Furthermore, the energy change consists initially of descent to the fin.ul altitude at near-constant indicated airspeed followed by a rapid alrspeed deceleration in level flight. Most of the energy change takes place at minimum throttle, as one might expect for minimum fuel flight. Minimum noise descent profiles computed in Ref. 7 are similar in that they al so delay the start of energy decrease as lung as possible, but they approach the final altitude in a steep descent to maximize the aircraft's altitude above the ground near the runway. This means that the deceleration to the fingl afrspeed takes place before the start of descent or during the early portion of the descent. Thus the two types of descent profiles differ prirarily in the way they proportion the use of available energy rate to decrease altitude and airspeed.

To facilitate the oynthesis of such profiles, a family of decreasing (and by extension, lncreasing) evergy profiles, which include the two types described as special cases, is defined by two parameters, $\sigma$ and $\varepsilon$. The first parameter, $\sigma$, selects the fraction of minimum/maximum avallable energy rate,
$\dot{E}_{n m i n}$, (Emax $E_{\text {ma }}$ to be used for decreasing/increasing energy. The values of $\dot{E}_{n m i n}$ and $\dot{E}_{\text {nmax }}$ can be read frum Fig. 1 at each indicated airspeed. The surunt parameter, $\varepsilon$, determines the fraction of the se!el ted energy rate to be used for deceleration/aciclerat.n. Then, for particular rnoices of ' and $=$, the encra:" rate, airspeed, flight-path angle, altitude, anc. horizontal distance are computed as follows:

$$
\begin{aligned}
& \dot{\mathrm{E}}_{\mathrm{n}}=\sigma \dot{\mathrm{E}}_{\mathrm{nmin}} \quad 0 \leqslant, \leqslant 1 \\
& \dot{v}_{\mathrm{d}}=g \varepsilon \dot{\mathrm{E}}_{\mathrm{n}} \quad 0 \leqslant \varepsilon \leqslant 1 \\
& \gamma_{\mathrm{a}}=(I-\varepsilon) \dot{\mathrm{E}}_{\mathrm{n}} \\
& \dot{\mathrm{n}}=v_{\mathrm{a}} \gamma_{\mathrm{a}} \\
& \dot{\mathrm{s}}=v_{\mathrm{a}} \cos \gamma_{\mathrm{a}}+v_{\mathrm{w}}
\end{aligned}
$$

where $v_{w}$ is the along-track component of wind speed. Note that Eqs. (7)-(9) are consistent with Eqs. (4) and (5) for all values of $\sigma$ and $\varepsilon$. Decreasing/increasing energy profiles are generated by integrating Eqs. (8), (10), and (11) for part1cular cholces of $\sigma$ and $\varepsilon$.

To 1llustrate the effect of the parameter $E$ on the descent/deceleration profiles, assume $\dot{E}_{n}=-0.13$, independent of speed, and let the airspeed to be achieved at touchdown be $100 \mathrm{ft} / \mathrm{sec}$. To achieve the desired boundary conditions, Eqs. (8), (10), and (11) are integrated in backward time starting with the speed and altitude at touchdown. The resulting atispced and altitude profiles are plotted as a function of distance to touchdown in F1g. 4 for $\varepsilon=1,0.5,0.0$. The profile for $\varepsilon=1$ is seen to approximate the minimum fuel, for $\varepsilon=0$, the mintmum noise descent, and for $\varepsilon=0.5$, a compromise between fuel and notse minimization.

To achieve mintmum fue] or no1se performance, changes in energy should be made at maximum rate. This is accomplished by setring $\sigma$ to unity and thereby following the $\dot{E}_{n m i n}$ contour during descent and deceleration. However, for the aircraft under study this yields energy rates too negative for safe operation in the terminal area at some airspeeds. A limit less than one 1s also necessary to reserve energy rate for perturbation control. A practical upper $11 \mathrm{mit}$ on $\sigma$ is abuut 0.9 for the AWJSRA. In the flight implementation, the two profile paraliters are keyboard entries that allow the pilot to choose values appropriate for each ianding approach. In addition, the pilot can specify the maximum deceleration and descent angles via keyboard entry. The maximum safe deceleration for this alrcraft is Iimited to about $0.06 \mathrm{~g}$ by the maximum rate at which flaps can be extended. The synthesis algorithm 1s conflgured to decrease $\sigma$ below its 11 mit if that is necessary to sat tsfy these constraints.

The backward time integration described above generates an increasing (In baikward time) energyprofile starting at the desired final speed and altitude. To complete the synthesis of the descent trajectory we still need rules for matchine this profile to the initlal speed and altitude of the aircraft. The freedom of the aircraft to maneuver in altitude is restricted by air traffic control as well as passenger comfort considerations. Thus, as an airctait approaches a terminal area, it is generally not allowed to climb above its initlal approach altitude for the purpose of optimizing the approach trajectory. The alrcraft must hold this altitude until starting the final descent. However, 
while flying at altitude $h_{1}$, 1t may change to a new alrspeed, $V_{a t}$ called the terminal-area speed which can be higher or lower than the initisl speed $v_{a 1}$. Unless specified by the pilot via ksyboard entry, 1t is chosen to minimize iuel use per unit distance, and is 140 knocs for this alrcraft (It would be 220-250 knots for conventional jet transports).

The various rules contained in the preceding two paragraphs can now be combined to yleld the complete algorithm. The synthesis begins with the backward time integration from final conditions $h_{f}, v_{a f} u s i n g$ the specified $\sigma$ and $\varepsilon$. If the altitude reaches its target value of $h_{1}$ before the airspeed reaches its target value of $v_{a t}$, we set $\varepsilon=1$ and then continue the backward time integration unt 11 the alrspeed has also achieved 1ts target value. When setting $\varepsilon=1$, the flight-path angle is forced to zero and the energy rate 18 used entirely for accelerating (in backward time) toward $v_{a t}$. On the other hand, if the afrspeed reaches its target value before the altitude does, we set $c=0$. This stops the alrspeed change and usus the energy rate entirely for increasing the sltitude toward its target value of $h_{1}$. When the second and iast variable reaches its target value, we set $\sigma=0$, 1.e., $\dot{E}_{n}=0$, thus completing the backward time integratioul. Next, we begin a forward time integration to get the distance required to change speed from $V_{a 1}$ to $V_{\text {at }}$ with $\varepsilon=1$. Let the discances for the rackwazd and forward integrations be $d_{b}$ and $d_{f}$, isspectively. A valld trajectory has been generated if the cruise distance $d_{c}$, computed from

$$
d_{c}=d_{h}-d_{b}-d_{f}
$$

is nonnegative, 1.e., $d_{c}>0$. If $d_{c}$ is negative, the synthesis has falled because the alrcraft is too close to the capture point $P_{f}$.

Figure 5 illustrates the various segments of an appruach trajectory synthesized by the algorithm. As before, wc assume for simplicity that $\dot{E}_{\mathrm{n}}=-0.13$, a constant. Other parameters defining the problem are indirated in the figure. Note that the initial descent at $\gamma_{a}=-7.5$ shallows to $\gamma_{a}=-3.75$ to allow the alrcraft to decelerate. The reference controls for this trafectory can be interpolated from F18. 1 .

We conclude this section by mentloning briefly other 1mportant features of the algorithm included in the flight implementation. The airspeed deceleration is corrected for known wind shears, which are computed frem a knowledge of $V_{w}(h)$ if avallable. The wind shear correction factor is

$$
\Delta \dot{v}_{a}=-\left(d v_{w} / d h\right) v_{a} r_{a}
$$

and 18 added to the rigit alde of Eq. (8) to ohtain the corrected alrspeed rate. Furthermore, the reference controls are corrected for the effect of the bouk angle used In flying a turn by interpolating the controls at an alrcraft welght multiplied by the load factor $2 / \cos \$$. Integration step size varles during oynthesis. During decelerations or accelerat lons it 1s 1 sec while during altitude changes at fixed speed It is $5 \mathrm{sec}$. Totel time for oynthesizing a complete trafectory consisting of a horisontal trajectory -1aflar to the ones shown In F18. 3 and a speed/ altitude profile siallax to the one in F18. 5 is about 2 sec on the Sparry Plight syotene 1819A alr- borne computer used in the flight tests. When the trafeciory synthesis is ime-shared with navigation and uther necessary computations, the computing time increases to about $6 \mathrm{sec}$.

\section{Real-Time Profile Generation}

After a profile has been synthesized in fast time and the pilot has elected to $i 1 \mathrm{y} 1 \mathrm{t}$, the reference states and controls for that profile must be generated in ceal time. The synthesized profile can contain discontinuous changes in roll and pitch engle and throttle and vectoring nozzle position at "command poiuts" where changes in speed, altitude, or heading are indilated or terininated. The real time profile generation therefore must provide a certain amount of lead $t$ ime to these control variables to minlmize tracking errors at command points. These functions are performed by the RealTime Profile Generation Logic.

If an on-board computer has a "ficlent memory capacity to store all of the retes. I states and controls during fast $t$ ! re synthesis at small intervals of time, this logic would be relatively simple. However, linitations on the storage avallable in the STOLAND computer mode this approach impractical. To minimize memory usage, a different method was implemented at the expense of Increased complextity of computation. The method consists of storing reference trafectory data, 1.e., control positions, speed, altitude, etc., only at the "comand points," as defined earller. Between "command points" the reference trajectory is generated in real time by the same integration logic used during fast time synthes1s; however, the integration is now done entirely in. forward time. Generation of alyable reference trajectory that meets the desired boundary conditions is guaranteed because it is a precise repetition of a previously successful synthesis.

The real-time forward Integration uses discume along the ground track as the independent variable. The integrated or dependent variables are reference $t$ ime, alrspeed, altitude, and heading. The cholce of distance rather than time gives a morf flexible and operationally improved system for the following reasons. In a distance-based reference trajectory system, the alrcraft will track the reference airspeed and altitude regardless of winds as it flles along the ground track. It 18 not necessary to null time errors if time control is not required. The system can thus be operated either in a 3D- or a 4D-tracking mode, depending on whether the time error loop is open or closed. This flexibility is lacking in a time-based reference trajectory aystem, where only the 40 tracking mode is possible. In the sime-based syutem, if the actual winds differ signiflcantly from the forecast winds used in fast-time trajectory synthesis, the alrcraft controls may have insufficient authority to track the reference position resulting in unacceptable tracking characteristics.

One difficulty with the dintance-based reference trajectory is that distance along the trajectory does not necessarily increase wotonically with time. Lerge navigation errore can cause tne new reference position to fall beh1ad the previous one or to move ahasd with a large step. This can result in control eyotem saturation during the critical descent and deceleration segmente. The ystem there ore containe logle that prevente the reference position from backIng up or fron advancing faster than about 1.5 tims 
the current ground speed between position updates, which occur at $100 \mathrm{msec}$ intervals.

\section{Perturbacion Guidance Law}

Perturbations of the alrcraft states from the reference states are used in the guidunce law to generate perturbation controls which are added to the reference contrcls in order to rull errors in alrspeed, altitude, and crosstrack position. The feedback states in the guidance law also inciude crosstrack error rate and fllght-path angle as well as the integrals of airsneed and altitude errors. The latter two are used to reduce speed and altitude bias errurs caused by inaccuracles in the stored energy-rate data and errors in the estimates of wind , id temperature profiles.

The controls are throttle, nozzle, pitch, and roll angles. Flaps are rot ised as perturbation controls because of their relatively low rate $11 \mathrm{mit}$ and an operational sonstraint that flap motion be monotonic during an apprcach. The flap command is simply the reference value at each ground track position limited to the placard value at the current alrspeed.

Lateral perturbation control is essentially uncoupled from the lingitudinal mode and is accomplished through a roll-angle command to the rollcommand autopilot. This command is of the form

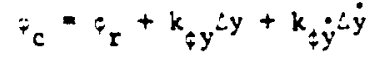

where. $i_{r}$ is the reference roll angle, and $i y$ and $\Delta \dot{y}$ are the crosstrack error and error rate, respectively. The two gains were chosen to provide 6 well-damped response and control activity crmpatthle with the noise characteristics of the ravigation syst:an.

Longitudinal perturbation control for correct. Ing airspeed and altitude errors is difficult because the refeterice controls generated by the energy-rate schedule of Fig. I often lie on a cunstraint beundary and therefore cannot be perturbed freely in both directions. The two controls that are of ten constraint 1 inited during a fuelconservative approach are throttle, - , and nozzle angle, $v$. Some insight inco this problem can be obtained using data from the energy-rate schedules. Figure 6 shows the energy-rate envelope $f$ rom Fig. I with the minimum reference nozzle and minimun reference throttle constraint boundarles. These boundarfes divide the envelope into four reglons: $I$, where $v$ cannot be reduced; II, where neither $\pi$ nor $\nu$ can be reduced; III, where $\pi$ cannot be reduced; and $I V$, where $\pi$ and $V$ are free to move in eith: $r$ direction. The combitiations of controls avallable for increasing and decreasing $\dot{E}_{n}$ in wach region are indicated in the figure. Note that in region $I$ nozzle could be used as an additional control var lable for decieasing energy rate, However, this variable is not used because throttle and pitch provide adequace control of flight-pach errors in this region. In reginn IV the sinimun raference throttle is above idle and is determined by the mapeuver arein conetraint. At each alropeed in thie region the negative throttle perturbaton that can be added to the raference throtele to yield the comended throtele is limited to $-2 \%$ for safery reasons. Positive and negative throtele perturbatious are further linlted so that the commanded throttle, $\pi_{c}$, falls in the engine operating range, $84 \%<\pi<96 \%$.

The perturbation equations and the perturbat. on cons::01 law can be written in stata vector nrtation as

$$
\begin{aligned}
\frac{d x}{d t} & =F x+c u \\
u & =k x
\end{aligned}
$$

winere

$$
\begin{aligned}
& \left.x=(L v, \Delta\lrcorner, i h, \int \leq v d t, \int \dot{h} d t\right)^{2} \\
& u=(\cdots,-i, i \nu)^{I}
\end{aligned}
$$

The delta quantitiss are the perturbatiuns from refterence values, 1.e., $L V=V_{a}-V_{a r}$, etc., where $V_{a}$ is the aircraft and $V_{a r}$ the reference true alrspeed, respectively. The commanded controls are the sum of reference and perturbation controls.

$$
u_{c}=\left(\pi_{I}+c \pi, \theta_{r}+i, \nu_{Y}+\Delta\right)
$$

For a powered-lift STOL alrcraft such as the one used for these flight tests, the values of $F$ and 6 are strongly dependent on airgpeed and energy rate and are thus time-verying alcng a trajectory. Q:1adratic Optimal Synthesis $\bar{F}$ would therefore yield tine-varying gain matrices that are also functions of the reference trajectory. But it is netther practical nor necessary to implement a complex, reference-trajectory-depencent gain matr $1 x$ in order to achieve adequate control system performance in. this case.

The design procedure employed here began by first computing optimum gain matrices at various operating points in the control region diagram (FIg. 1) using fixed values of $F$ and $G$. The analysis of these $z^{2}$ in matrices showed the strongest dependence on airspeed, reference nozzie angle, and icference rlaps. Sensicivity of the closed-10op eigenvalues to changes in several of the gatiss ias low, allowing those to be set to zero or held constant throughout the operating region. It was possible to fit the variable gains with relatively simple functions of reference airspeed, nozzle angle, and ilap angle. This method resulted in the fo' lowing eain matrix:

$\mathbf{k}=$

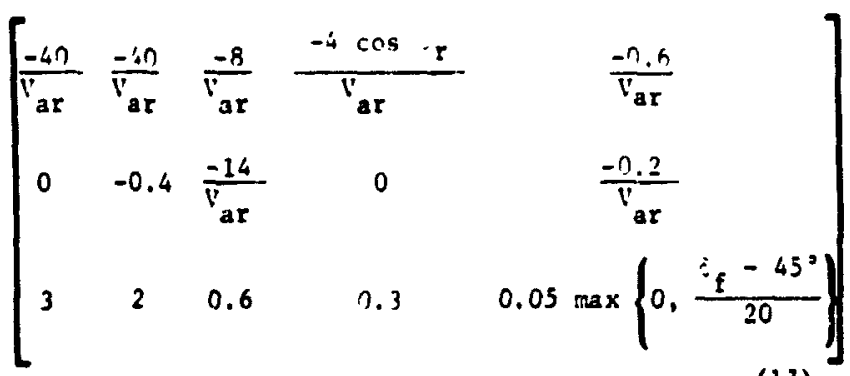

where $V_{a r}$ is in units of $f t / s e c$. Extensive

computer calculations have verifled that the closedloop eigenvalues of this system have damping factors of 0.707 or greater and real parts ixss than $-0.03 / \mathrm{sec}$ at all sperating points. These characteristics pruvide adequate tracking peiformance. When 
operating in region $I$ of $\mathrm{Fig}$. 6 the lasi row of $K$ is set to zero since nozzle angle is not used for control. In regions II and IIt throttle perturbations are limited to posittve values, while in region II nozzle perturbations are limited to positive values. In region IV each control moves freely, but negative throttle perturbations are limited to $-2 \%$ RPM as previously explained. Control 1imiting can reduce the effectiveness of integral feedback of speed and altitude. Some design considerations for these integral feedback loops are given in Ref. 9.

The throttle and nozzle angle perturbations generated by the control law will generaliy be of opposite $1 \mathrm{gn}$, because the elements of the firat row of $K$ all have opposite sign of the third row elements. Thus, even in region II, where throttle and nozxle perturbations are each imlted to move only in the positive direction; they are not generally limited simultaneously. This implies that two contruls, elther throttle and pitch or nozzle and pitch, arc free to move. Transient response studies using a nonlinear asmulation of the alrcraft and guldance system have shown that the control power 1.2 adequate to provide rapid and well-damped airspeed and altitude error responses in region II. Example transient responses from this simulation are discussed in the last section.

\section{Structure and Operation of the Flight System}

The integration of the functional unzts of the system is shown in Fig. 7. Computations begin in the fast time trajectory synthesis module. If a trajectory 1s successfully synthesized, it is stored at comand points, as previously explained, and the aynthesized horizontal trajectory is displayed to the pilot on an eleccronic liorizontal Map Dispiay (HMD). This display operates in conjunction wi: the navigation system to give a map-like view nf the terminal area (see Ref. 2 for detalls on this device). If the track switch 1s engaged, real-time prof 1le generation and closed-loup tracking of the synthesized trajectory begins. The four control varlables generated by the perturbation feedback law drive the roll and pitch autopllots and the throstle and vectoring nozzle servos.

Figure 8 gives on example of trajectorles displayed on the HMD. The solidly drawn track is a flxed and prestored reference trafectory on which waypoint numbers are indicated. The pilot selects the waypoint on the flxed reference trafectory he wishes to capture by keyboard entry (waypoint 2 in this case). The track drawn with broken lines from $P_{1}$ to 2 Indicates to the p1lot that a valld capture trafectory to that waypofint has been computed. If the synthesis had not been successful, the synthesis routine would have been reentered, as shown in Fig. 7, with updated eircraft sta:es as the new inicial conditions.

To account for the distance the aircraft will travel whlle the trajectory is being synthesized and to glve the pllot time to push the track owitch, the capture trajectory is actuiliy computed from $P_{2}$ rather than $f$ row the alrcraft position at $P_{1}$ (wee F18. 8). The short, atraight engent between $P_{1}$ and $P_{2}$ is referred to as a lead diatance and it is drawn alons the alreraft velocity vector at the etart of synthesis. This technique minimizes Initlal condieton arrors at the baginning of the witcimatic-tracking mode.
After the reference trajectory has been stored and valid navigation data from TACAN ${ }^{\dagger}$ or MODIL.5 are received the track swltch (see F1g. 7) 1s armed, rtady for the pilot to engage. If the pilot does not engage the track switch before the alrcraft reaches $P_{2}, P_{2} 18$ moved to 1 ts new position, and a new capture crajectory is displayed ir one were successfully computed. When the pllot engages the track switch as at $P_{1}$ in $F 1 g .8$, the capture path on the display 1s drawn with a solid line indirating to the pilot that closed-10op guldance to the synchesized trajectory has bezun.

While the capture-trafectory algorithm synthe- izes successful trajectorles for a wide range of initial conditions, there are conditions where it will fall to do so. For example, if $P_{1}$ is very close to the captire waypoint, then the algorithm can fatl because chere is Insufficient distance along the computed minimum distance path to complete the required change in the speed and/or altitude. In that case, the reason for the fallure to synthesize is displaycd as a short message on the FMD. The pilot can correct the fallure to capture cond1tion by flying the alrcraft away from the capture waypoint or by selecting a more distant capture waypoint.

The fixed reference trajectory, though not always usable as explained in the introduction, prescribes a nominal approach route and 18 determined by air-traffic control and terminal-area constraints. The precise alrspeed and altitude proflles alone. this fixed reference usually are not rigidiv specifled. Often the airspeeds and altitudes are spectfled only at waypoints. In that case the speed and altitude profiles between adjacent wavpoints are sunthesized in fast time using the same algorithm as for the capture trafectory. The synthesis is done in backward tine starting at the last waypoint and ending at the canture waypoint. The altitude and speed at wavpoint $:-1$ determine the final condition and the altitude and speed at waypoint $N$ determine the intial condtion for the sunthesis. Thus, every avallable degree of freedom is explotted to optimize the total trajectory.

\section{Simulation and Flight Test Results}

The performance of the guldance syatem was evaluated in simulation and flight tests. The piloted s i tulator was the primary tool for determining the performance limits of the system since tt allowed the measurement of performance for known disturbance inputs. In flight, it is difflcult to measure or control disturbances and lsolate their effect on performance. Filght tests were used to verify the simulator model and to obtain pllot comments on the operational accsptability of the system.

Figure $9(a)$ gives simulator time histortes of selected states and controls for a combined capture and flxed approsch trajectory, from $3000 \mathrm{ft}$ alestude, $140 \mathrm{KEAS}$, and $40,000 \mathrm{ft}$ to touchdom. The

t'TACtical Alr Navigation Syaten providas aximuth and range relacive to etation locacton.

popular Inetrument Landing System is an intert microwave landing syst with a asimuth scan of $\pm 20^{\circ}$, an elevation scan of $16^{\circ}$, and a prectetion distance masurine eyeten with a range of $10 \mathrm{n}$. at. 
initlal positior. and heading were chosen to yield a more cr less atralght-in horizontal capture path along the extended centerline of the runway. Waypoint 2 of the flxed-reference path shown in Fig. 8 was selected as the capture waypoint. The capture tiajectury cunsists of a constant speed, level flight segment to point $A$ where a $-7.5^{\circ}$ descent begins. Deceleration at $0.05 \mathrm{~g}$ starts at point $B$ whlle the aircraft is in descent. The deceleration is intelated by starting the deployment of flaps (not shown in the flgure). End of capture and the start of the final-approach trajectory is at point $C$, which corresfonds to waypoint 2 in F1g. 8, where tre alrcraft has decelarated to the landing speed ot 72 XEAS and 15 tracking a $-7.5^{\circ}$ glide slope.

Point $C$ is 700 ft above the rumway and about $5400 \mathrm{ft}$ from touchdown. Automatic tracking is termineted at point $D$ (Waypoint 1 in Fig. 8), $300 \mathrm{ft}$ above the runway and $2280 \mathrm{ft}$ from the nominal touchdown point. The capture trafectory was synthesized using a minimum flight-path angle of $-7.3^{\circ}$ and $a$ maximum deceleration of $0.05 \mathrm{~g}$. The parameters 0 and $c$ were set to 0.9 and 1.0 , respectively. The cholce of $E=1$ gives the priority to deceleration during the combined deceleration and descant segmencs. Th1s combination of $11 \mathrm{mits}$ and parameter values resulted in a reduction in flight-path angle from $-7.5^{\circ}$ to $-6.9^{\circ}$ Eor a 10 sec perlod just prior to point C. Both the synthesis algnrithm and the alrrraft simulator assumed zero wind speed, a standard temparature profile, and an aircraft weight of 48,000 1b. Navigaction errors were set to zero. The tracking perfozmance of the perturbationcontrol law under these nominal conditions serves as a standard against which the performunce under off-nominal and fllght-test conditions can be evaluated.

The step throtile reduction to $84 \%$ KPM and the pltch down comand (not shown in Fig. 92) lead the computed descent puint at poine $A$ by about $6 \mathrm{sec}$ to compensate for ttizottle- and pitch-anglo dynamics. This prevents overshoots in tracking the refarence altitude at the point of descent. The smail altstude transient at this point is damped in about 5 sec. Speed and altitude er:ors during the deceieration and descent segment between points $B$ and $C$ never exceed 4 knots and $20 \mathrm{ft}$, respectively These exrors converge to zero between points $C$ and $D$. Though of no practical significance, the restdual errors during deceleration are caused by insccuracies in the raferenc: throtele. nozzle, and pltch comands computed from the energy rate performance tables during fast tine synthesis. The respanse of the perturbation control law to these modeling Inaccuractes is seen as the difference between the superimposed traces of comanded and reference nozzie and throt:le angles in Fis. 9s. These differences are small wen while reference nozzle and throtele angles are increasing capidly toward the end of the decleretion segment. The velldity of the energy-rate-performance nodel os an eccurate predictor of afreraft performance during these quasi-dynamic maneuvers is thus verifled.

Figure 9b show the cait.trol systen response to a i0-knot headerind pulse of about 70-sec duration uelng the cane reference erajectory at in Fis.98. The instial epeed errot resulte ing from this pulse is rapldiy damped by unlns the possle as control. Then, intereal apeed and altitude teedback develops th.ottle-, norele-, and pitch-perturbation biases in about 20 eec to correct the raference controle for the change in aerodymanic tlight-path angle caused by the change in the mean wind. In effect, the integral feedhack serves as an est imator of the mean wind. When the headwind pulse is removed just after point $C$, the effect is equivalent to a tallwind pulse and results in another transient. Note that the introduction of the headwind pulse has increased the $t$ lme between points $B$ and $C$ because tie ground speed is reduced. Crosstrack position errors, though not shown, zemain neg11";bly small during the approach.

Other simulation results have shown that the control lar can compensate for unmodeitd tailwinds and headwinds of 15 and 25 knots, rospe:tlvely, without exceselve control saturation. Also, exrors of $10 \%$ in alrcraft weight and $+20^{\circ} \mathrm{C}$ and $-10^{\circ} \mathrm{C}$

unmodeled temperature devlations from that assumed are compensated by the control law.

Figure 10 shows various time historles for a straight-in flight-test approach under conditions -imilar to thuse in the simulations. One significant difference was the use of .038 maximum deceleration in the flight test. This cauced the deceleration to begin at point $A$ before the point of d-scent at $B$. The entire approach trajectory was flown using TACAN for navigation. The locatior of the IACAN station relat lve to the runway is shown in Fig. B. Because of lts favorable location, the TACAN station provided sufficlent navigation accuracy for flying the approach without swttching to the higher preciston MODILS as would normally be required. There was light to moderate turbulence and an average headwind of about 15 knots below $4000 \mathrm{ft}$ as measured by a radar-tracked weather balloon just p=lor to takeoff. However, the wind proftle was not entered into the synthesis logic and thus constituted an unmodeled wind. Altitude errors, except near the pitch-down point, did not exceed $35 \mathrm{ft}$ and decreased to about 15 fe noar the end. Speed errors during deceleration were less than $10 \mathrm{ft} / \mathrm{sec}$, and decreased to about $1 \mathrm{ft} / \mathrm{sec}$ at the end. If allowance is made for the presence of turbulence, winds, and navigation-system nolse durling the flight, these errors agree reasonably well with the sinulation results and are acceptably low. The control perturbation blases, evidently caused by modeling errors and the unmodeled wind, are larger than those seen in the simulation run of Fig. $9 \mathrm{a}$, though they are not excessive. Nozzle blas during the middle of the deceleration averages about $25^{\circ}$. While this seeme large it should be noted that during this interval the throttle is at flight idle, where the effect of nozzle on energy rate 1 a ainimum. On tine whole, the control bisses represent fairly sall errors in the energy rate moded. The flight-test resuits can, of course, be used to Improve the arcuracy of the anergy-rate model of the aircraft.

The erosetrack error at point $D$ masured by precistion radar was $80 \mathrm{ft}$ or less than half the width of the rumay. Th1s error, which the pilot can null during manuel ilighe from poine $D$ (waypoint 1) to touchdown, approaches the accuracy ilatte of TACAN. At the same time 1t sets a lower linit on the distance between point $D$ and touchdown when using TACAN. Fllots judged the action of the control law as amooth end the capture trajecenry as a conventent and effective tool for optinizing approsch srajectortes.

The tuel consumption of this automaticaily flown trajectory was compered with that of a trajectory tlown ty a test pllot under elmulated 
inetrument-f11ght-rule conditiona, In order tw provide basio for comparison the manually flown trafectory began frow the same intelal distance-tctouchdown, alrepeed and altitude as the autonet1cally flown trajectory. The approach was made with the ald of a flight-director systen which dieplayed to the pllot lateral and longltudinal devincione from atraight-in, $7.5^{\circ}$ approsch path. The fuel ues for the automat ic approach was $381 \mathrm{lb}$, wile that for the manuily flown one was $5001 \mathrm{~b}$. Further simulation and flight tests should be conducted to compare the fuel consumption for varlous approach trajector 1es, f) ight-director designs, and wind conditions beforz the fuel conservation potential of this guldance syerem can be considered etcablished.

\section{Concludino Remarks}

The automatic guidance syeter described in this paper achseves the dual goal of fully autometic flight and near-optianl fuel conservat ion through the technique of fast-time onboard trajector: synthesis. This technique overcoms the performance IImitations inherent in a etored, precalculated trajectory by adapting the trajectory to the unique conditions encountered in esch landing epproseh. The ability to adapt is crucial in the cerninal area - Ince the Inteinl conditions for etarting the approsch and the uind and temperature proflles are not predictable with sufflcient accurecy prior to cakeoff. The cechnique for aynthesizine the trajectorles allowe the pllot to choose varlous deculeration/descent profllus. All proflles have the comon characteristle of delaying the etart of the descent and deceleracion points as much so posc1ble. A prelininary flight evaluation indicates thet an automelcally flown, optimin approach can produce significant fuel sevings relative to on approach flown manully with only convent lonal f1sht-director culdance. The deaten procedure described herein for a STOL elrcraft is appliccble with leseer control complextty to susdance syetem desien for CTOL alrcraft.

\section{References}

INeumeit, Frank, Watson, Delamar M., and Bradbury, Peter, "Oparational Deseription of an Experimental Digltal Avionics system for STOL A1rplanes, NASA TM X-62,448, Dec. 1975.

ZLe, Homer Q., Neuman, Frank, and Hardy, Cordon G.. "4D Area Navigation System Descriptior and Fl1ght Testa," NASA TN D-7874, Aijg, 1975.

${ }^{3}$ Bryson, A. E., Jr., Desad, M. N., and Hot,ilan, W. C., "Energy Stace Approximation In Perfornaice Optimization of Supersonic Alrcraft," Journal of Alrcrefe, Vol. 6, Nov.-Dec. 1969.

"Eraberger, He1nz, and Lee, Homer Q., "TerminalAres Guldance Nigorithms for Automated Alr Traffic Contro1," NASA IN D-6773, Apr 111972.

Specevered1, Thomes, "Four-Dimensional Guldance Algorithwe for Aircrafe in an Air Traftic Control Environment," MASA TN D-7829, March 1975.

GEraberger, Heinz, Kclean, John D., and Berman, John F., "Flxed-Range Opt Imum Trajectories for ShortHaul Aireraft," MASA IN D-8115, Dec. 1975.

7Jakob, Heinrich, "An Engineering Optinlietion Method wth Applicetion to jiol Alrcraft Approach and Lending Trajectorles," MASA TM D-6978, Sept. 1972.

OBryson, A. E., Jr. and Ho, Y. C., "Applied Optiel Control", Blalsdell Piblishins Co., 1969.

Islater, Gery, "Analvele of Integral Controis in Linear quadratic Rogulator Design." AIAA Guidance and Control Conterence, Aup. 6-8, 1979, Boulder. Coloredo, PP. 79-1743.

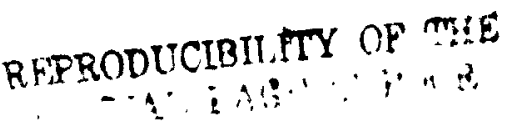




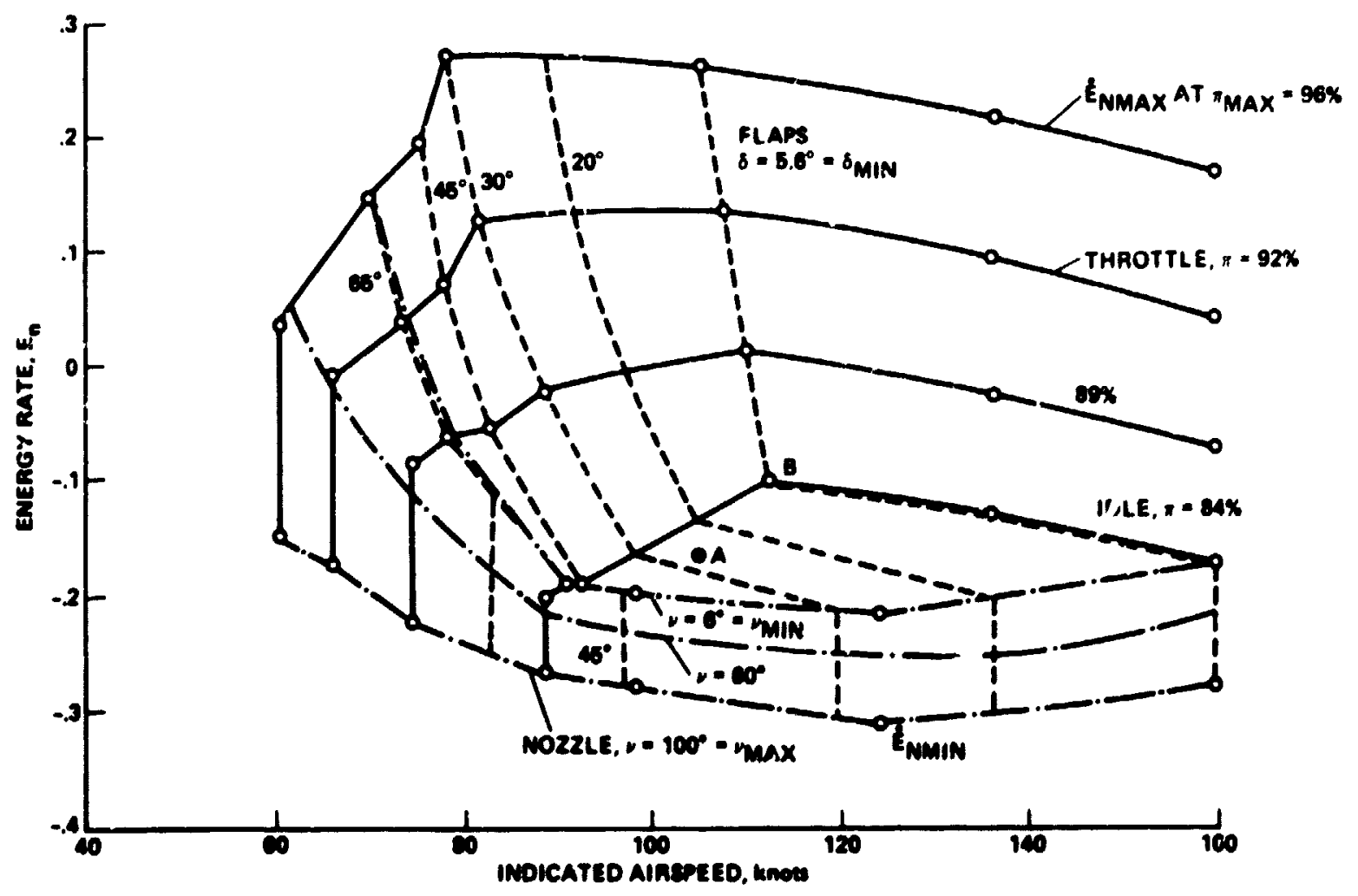

T15. I Energy rate diegran for stol afreraft; $W \cdot 38,000$ 10, sea lavel $59^{\circ}$ P.

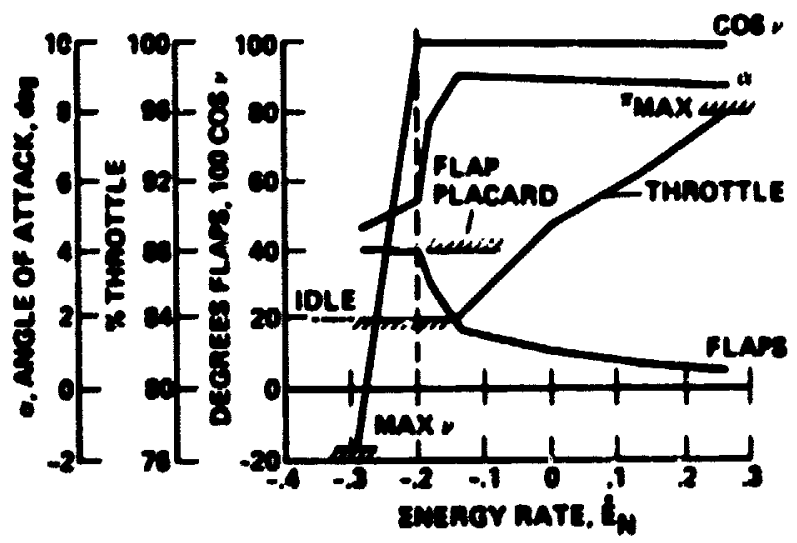

Mg. 2 Optime controle es function of morgy rato

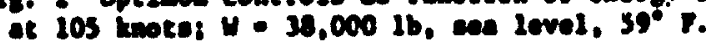

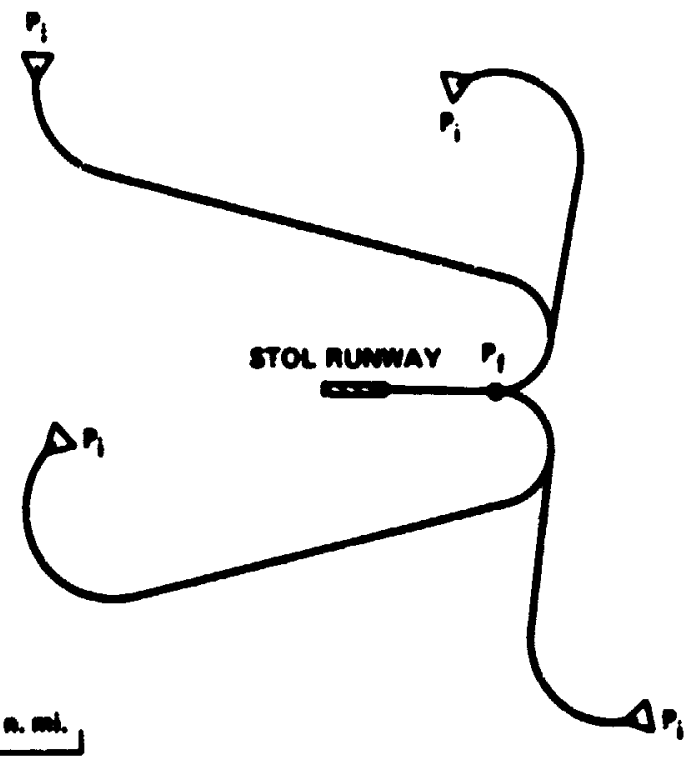

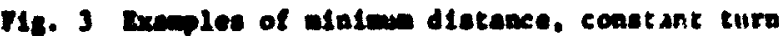
redlus, borisental eapture trejectories to a capture polat if on fteid epprasch. 

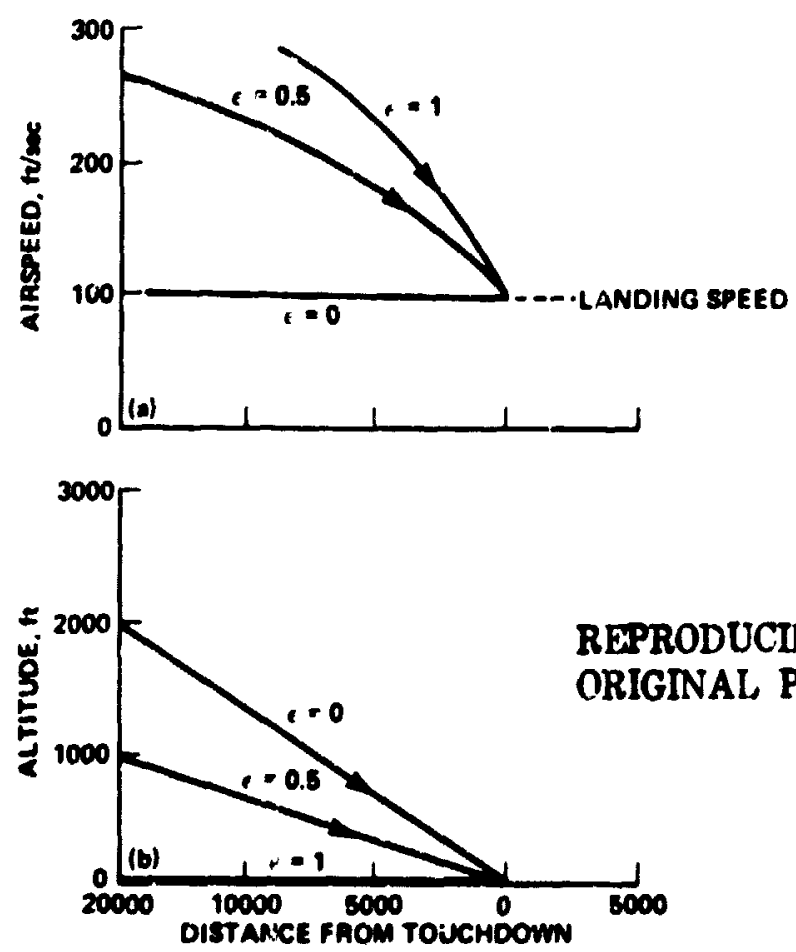

F18. 4 Effece of $c$ on epeed and alticude profilce, with $\dot{E}_{n} \ldots 13$.

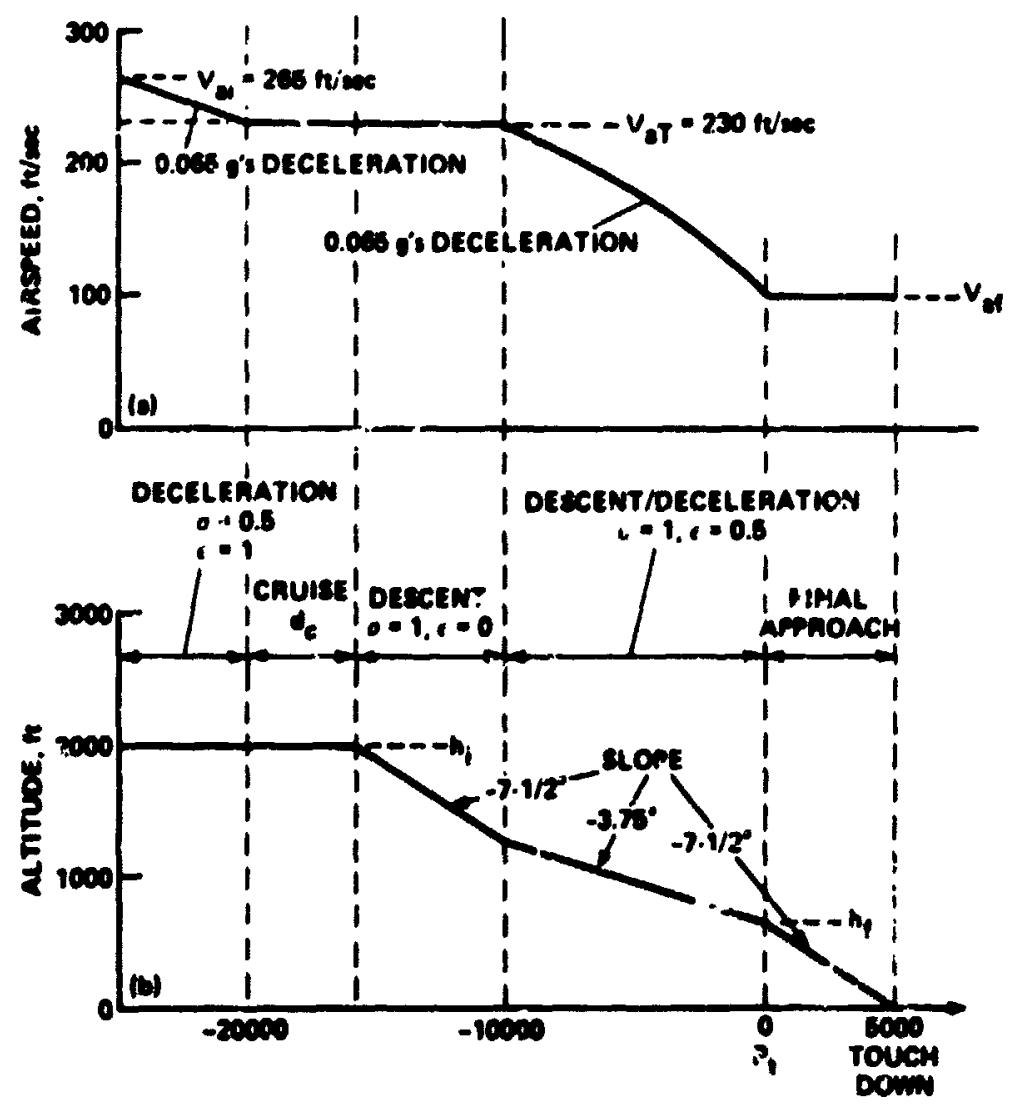

r1s. I tuanple of aratbealsed stol apprasch trajectory. 


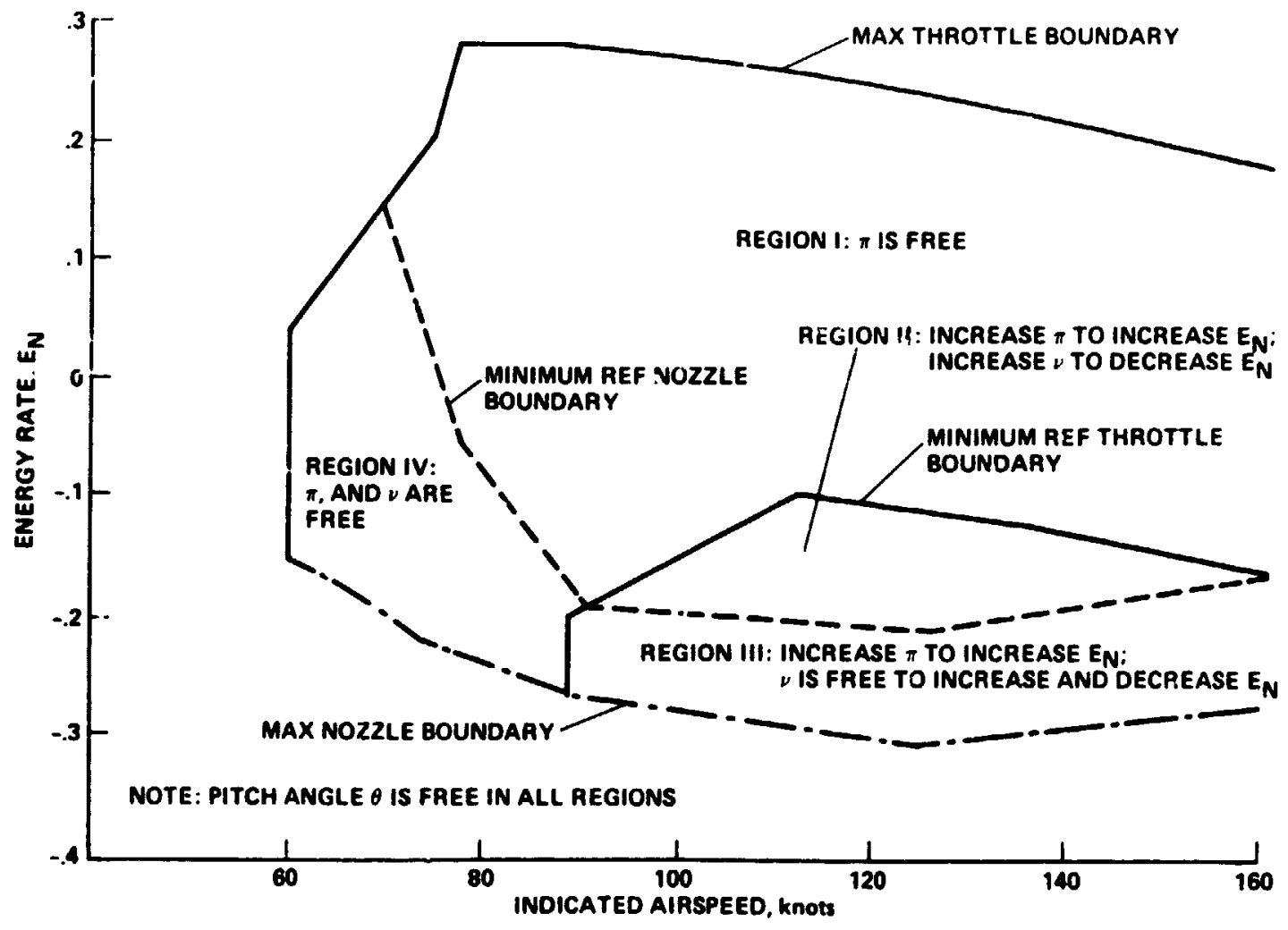

FAB. 6 Constraint boundaries for perturbation controls. 


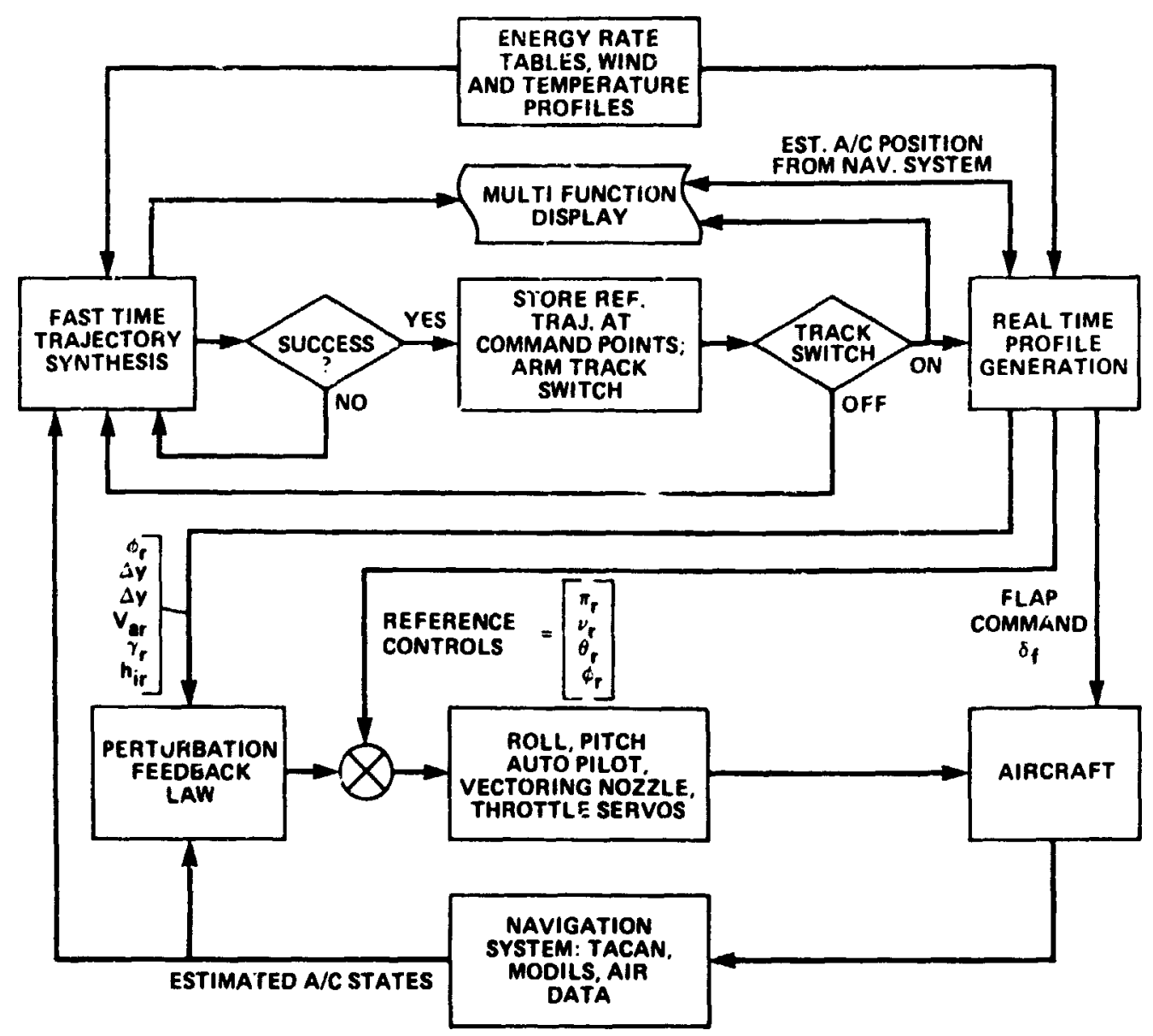

Fig. I Block diagrami of guidance system.

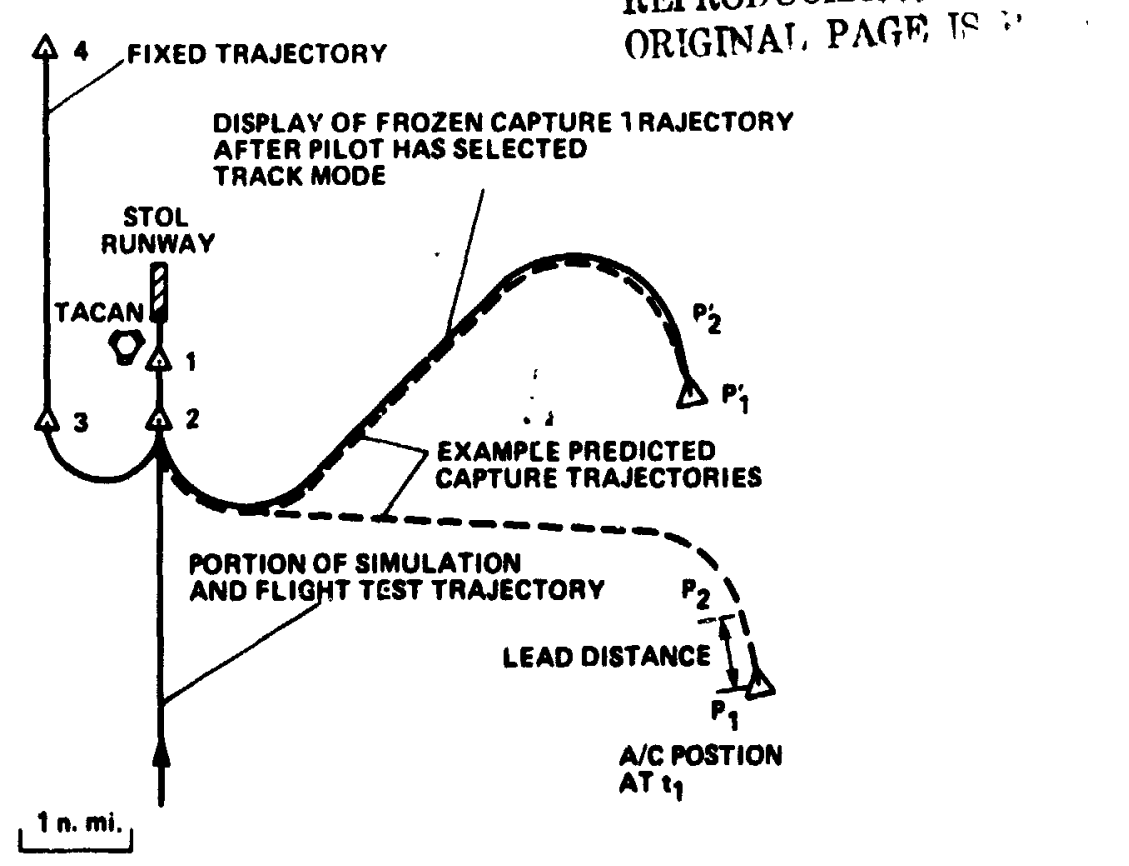

Fig. 8 Horizontal flight paths dioplayed on cockpit Horizontal Map Dinplay (HM). 


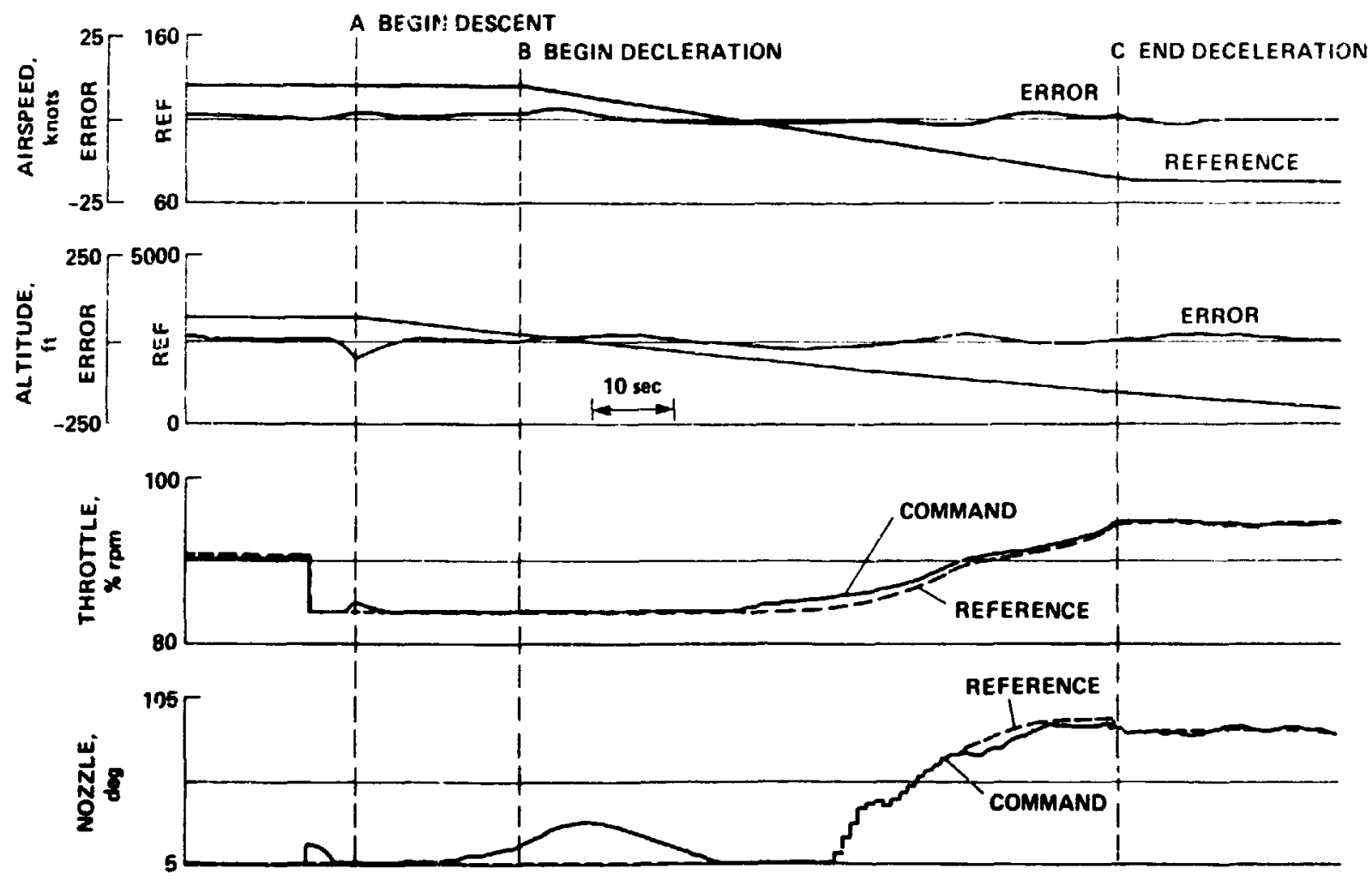

(a) Nominal conditions.

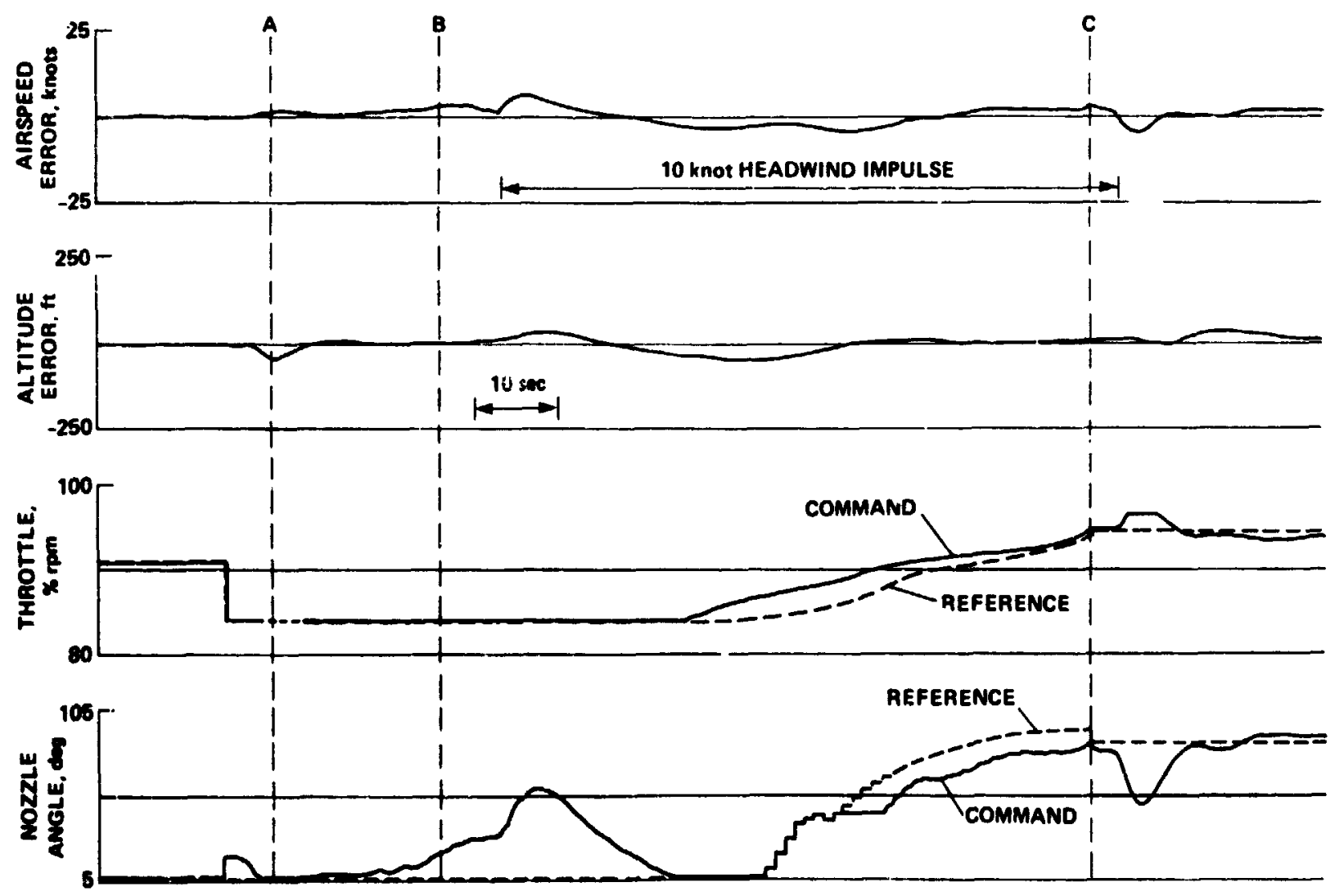

(b) Effect of 10-knot headwind Impulse.

7ig. S Simulation of typical approach trajectory; runway at 140-ft A.S.L. 


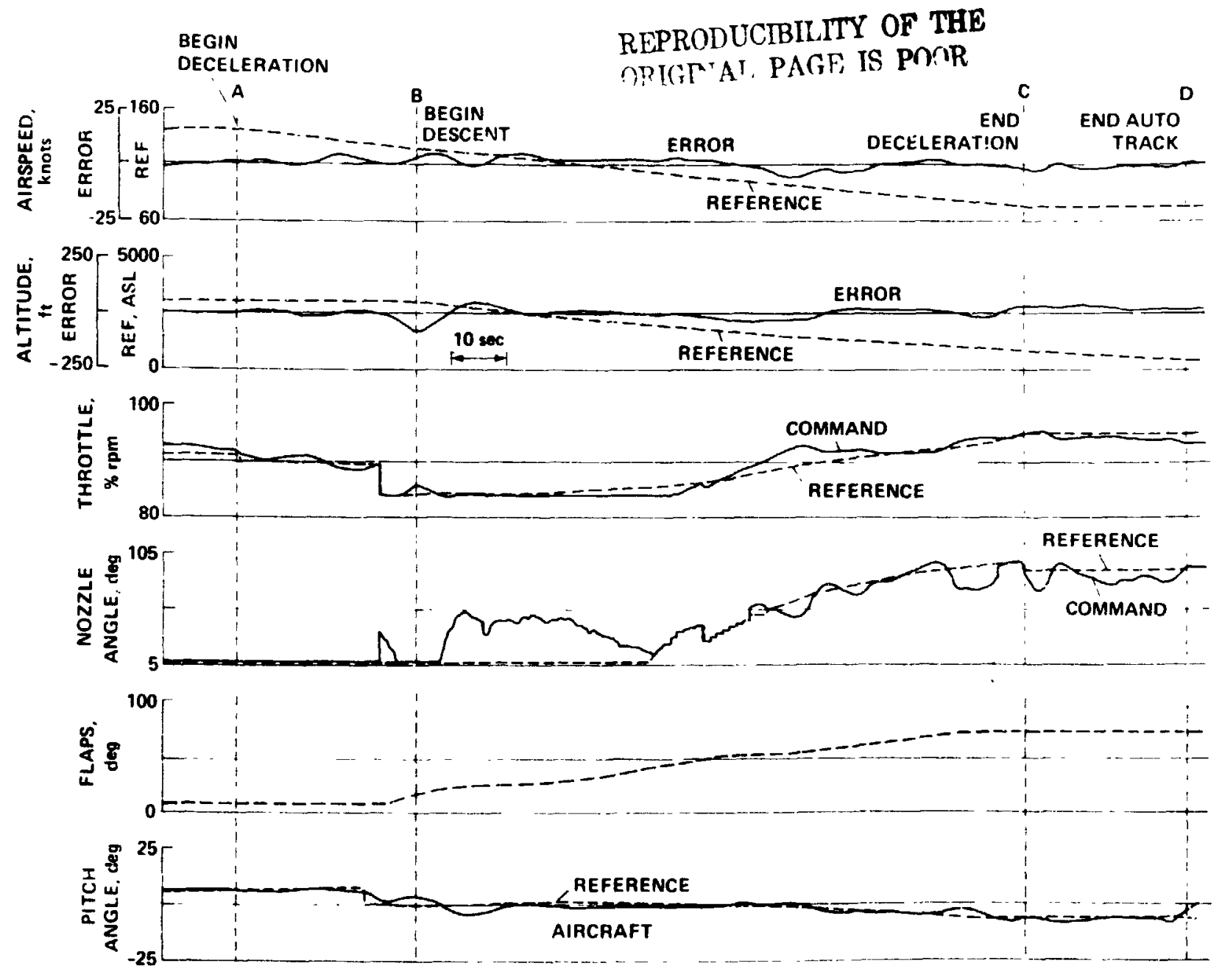

Fig. 10 Flight-test results, runway at 140-ft A.S.L. 


\begin{tabular}{|c|c|c|c|}
\hline $\begin{array}{l}1 \text { Report No } \\
\text { NASA TM-78595 }\end{array}$ & 2 Government Accession No & \multicolumn{2}{|c|}{3 Recipient's Cataiog No } \\
\hline \multicolumn{2}{|c|}{ Titie and Subitle } & \multicolumn{2}{|l|}{ 5. Peport Date } \\
\hline \multicolumn{2}{|c|}{$\begin{array}{l}\text { FLE: -CONSERVATIVE GUIDANCE SYSTEM FOR POWERED-LIFT' } \\
\text { AIB: RAFT }\end{array}$} & \multicolumn{2}{|c|}{ 6. Ferforming Organization Code } \\
\hline \multirow{3}{*}{\multicolumn{2}{|c|}{ He $\llcorner$ nz Erzberger and John D. McLean }} & \multirow{2}{*}{\multicolumn{2}{|c|}{$\begin{array}{l}8 \text { Performing Orgarization Report No } \\
\text { A-7860 }\end{array}$}} \\
\hline & & & \\
\hline & & \multirow{2}{*}{\multicolumn{2}{|c|}{$\begin{array}{l}10 \text { Work Unit No } \\
505-07-11\end{array}$}} \\
\hline \multirow{2}{*}{\multicolumn{2}{|c|}{$\begin{array}{l}9 \text { Perlorning Organization Name and Address } \\
\text { Ame: Research Center, NASA } \\
\text { Mof fett Field, Calif. } 94035\end{array}$}} & & \\
\hline & & \multicolumn{2}{|c|}{11 Contract or Grant No } \\
\hline & & \multirow{2}{*}{\multicolumn{2}{|c|}{$\begin{array}{l}13 \text { Type of Report and Perrod Covered } \\
\text { Technical Memorandum }\end{array}$}} \\
\hline \multirow{2}{*}{\multicolumn{2}{|c|}{$\begin{array}{l}\text { 12. Spon. ing Agency Name and Address } \\
\text { Nat. Lonal Aeronautics and Space Administration } \\
\text { Was aington, D.C. } 20546\end{array}$}} & & \\
\hline & & \multicolumn{2}{|c|}{14 Sponsoring Agency Code } \\
\hline \multicolumn{4}{|c|}{$\begin{array}{l}15 \text { Supplementary Notes } \\
\text { Paper for AIAA Guidance and Control Conference, Aug. 6-7, 1979, Boulder, Co. }\end{array}$} \\
\hline \multicolumn{4}{|c|}{$\begin{array}{l}\text { A concept for automatic terminal-area guidance, comprising two modes of } \\
\text { of } 2 \text { ration, has been developed and evaluated in flight tests. In the first or } \\
\text { prodictive mode, fuel efficient approach trajectories are synthesized in fast } \\
\text { time. In the second or tracking mode, the synthesized trajectories are } \\
\text { re onstructed and tracked automatically. An energy rate performance model } \\
\text { del ived from the lift, drag, and propulsion system characteristics of the air- } \\
\text { crat is used in the synthesis algorithm. The method optimizes the trajectory } \\
\text { for the initial -ircraft position and wind and temperature profiles encoun- } \\
\text { tered during each landing approach. The paper describes the design theory } \\
\text { and discisses the results of simulations and flight tests using the Augmentor } \\
\text { Wing Jet SToL Research Aircraft. }\end{array}$} \\
\hline $\begin{array}{l}\text { 17. Key } W \text { ts (Sugpested by Author }(s) \text { ) } \\
\text { A. ronalit-ics } \\
\text { Navigat:ion } \\
\text { Guidance }\end{array}$ & & \multicolumn{2}{|c|}{$\begin{array}{l}\text { 18. Distribution Stutement } \\
\text { Unlimited } \\
\text { STAR Category - } 01\end{array}$} \\
\hline $\begin{array}{l}\text { 19. Security } a_{\text {wif }} \text { il thus roport) } \\
\text { Unc Iasisified }\end{array}$ & $\begin{array}{l}\text { 20. Sacurity Classif. (of this papol } \\
\text { Unclassif Ied }\end{array}$ & $\begin{array}{l}\text { 21. No. of Pages } \\
17\end{array}$ & $\begin{array}{l}\text { 22. Price } \\
\$ 3.50\end{array}$ \\
\hline
\end{tabular}

"For sale by the National Ter.hnical Information Service, Springtield, Virginia 22161 